\title{
Stage II Prostate Cancer AJCC v8
}

National Cancer Institute

\section{Source}

National Cancer Institute. Stage II Prostate Cancer A/CC v8. NCI Thesaurus. Code C140165.

Stage II includes: IIA: (CT1a-c, cT2a, NO, MO, PSA equal or more than 10 and less than 20, Grade Group 1); (cT 2b-c, N0, M0, PSA less than 20, Grade Group 1); IIB: T1-2, N0, M0, PSA less than 20, Grade Group 2; IIC: (T1-2, N0, M0, PSA less than 20, Grade Group 3); (T1-2, N0, M0, PSA less than 20, Grade Group 4). cT 1a: Prostate cancer in which the tumor is an incidental histologic finding in 5\% or less of tissue resected. CT 1 b: Prostate cancer in which the tumor is an incidental histologic finding in more than $5 \%$ of tissue resected. CT 1c: Prostate cancer in which the tumor is identified by needle biopsy found in one or both sides, but not palpable. CT2a: Prostate cancer in which the tumor involves one-half of one side or less. cT 2b: Prostate cancer in which the tumor involves more than one-half of one side but not both sides. CT2c: Prostate cancer in which the tumor involves both sides. T1: Prostate cancer with clinically inapparent tumor that is not palpable. T2: Prostate cancer in which the tumor is palpable and confined within the prostate. N0: Prostate cancer with no positive regional nodes. M0: Prostate cancer without evidence of distant metastasis. Grade Group 1: Gleason Score 6 or less, Gleason Pattern 3 or less+3. Grade Group 2: Gleason Score 7, Gleason Pattern 3+4. Grade Group 3: Gleason Score 7, Gleason Pattern 4+3. Grade Group 4: Gleason Score 8, Gleason Pattern 4+4. (AJCC 8th ed.) 